\title{
PENGELOLAAN SAMPAH DI RUMAH SAKIT ISLAM PURWOKERTO KABUPATEN BANYUMAS TAHUN 2015
}

\author{
Imam Suerdi ${ }^{1}$, Budi Triyantoro ${ }^{2)}$ \\ Jurusan Kesehatan Lingkungan, Politeknik Kesehatan Kemenkes Semarang, \\ Jl.Raya Baturaden KM 12 Purwokerto, Indonesia
}

\begin{abstract}
Abstrak
Rumah sakit sebagai salah satu sarana pelayanan kesehatan, tempat berkumpulnya orang sakit maupun orang sehat, atau dapat menjadi tempat penularan penyakit serta memungkinkan terjadinya pencemaran lingkungan dan gangguan kesehatan.Rumah Sakit Islam Purwokerto Kabupaten Banyumas merupakan rumah sakit yang menghasilkan sampah dari setiap kegiatan yang dilakukan di rumah sakit. Tujuan penelitian ingin adalah untuk mengetahui pengelolaan sampah di Rumah Sakiit Islam Purwokerto Kabupaten Banyumas.Metode yang digunakan dalam penelitian ini adalah metode deskriptif yaitu menggambarkan pengelolaan sampah medis di RS Islam Purwokerto Kabupaten Banyumas.Hasil penelitian yang didapatkan yaitu rata-rata berat sampah medis adalah $27,5 \mathrm{Kg} /$ hari dan rata-rata volume sampah non medis adalah 711,42 liter/hari, sudah ada lingkup kegiatan pengelolaan sampah medis untuk pelaksanaan pengelolaan sampah medis agar menjadi baik, tetapi dalam pelaksanannnya masih ada yang belum sesuai dengan lingkup kegiatan tersebut. Pelaksanaan yang belum sesuai adalah masih adanya sampah non medis yang tercampur di tempat sampah, kapasites TPS medis kurang memadai, pengumpulan sampah tidak menggunakan jalur khusus, pengangkutan sampah medis dilakukan setiap hari Rabu dan jalan mепијu TPS medis sempit.Simpulan penelitian ini adalah penilaian pelaksanaan pengelolaan sampah medis masuk dalam kategori baik dengan skor 77,77\%. Peneliti menyarankan sebaiknya melakukan pemantauan setiap hari oleh petugas dari tahap penimbulan sampah sampai tahap pemusnahan sampah, sehingga pelaksanaan pengelolaan sampah di rumah sakit dapat berjalan dengan baik.
\end{abstract}

Kata Kunci : Pengelolaan sampahrumah sakit

\begin{abstract}
Hospital as one of the health-care facility, a gathering place where the sick and healthy people, it can be a disease transmission place and also lead environmental pollution and health problems. Islamic Hospital Purwokerto, Banyumas Regency is hospitals that generate waste from its activities. The research objective was determining the waste management in the Islamic Hospital Purwokerto, Banyumas Regency. The research method used was descriptive method that describes the waste management in Islamic Hospital Purwokerto Banyumas Regency. The research result shows that the average medical waste weight was $27.5 \mathrm{Kg} /$ day and the average nonmedical waste volume was 711.42 liters/day, there were medical waste management activities for medical waste management in order to be better, but some of the practice did not appropriate with the scope. The implementation that did not appropriate was; non-medical garbage mixed in the trash bin, inadequate temporary waste medical storage capacity, garbage collection does not use a special lane, medical waste pickup was conducted every Wednesday and the allay leading to temporary medical waste storage was too narrow. The research conclusion drawn was; the medical waste management implementation assessment categorized as "good" with percentage score $77.77 \%$. Researchers suggest the officers to monitor daily waste management activities in each phase from waste stacking untill extermination, so that the hospital waste management implementation could conducted properly.
\end{abstract}

Keywords : Hospital Waste Management

\section{PENDAHULUAN}

Kesehatan lingkungan dapat tercapai dengan mewujudkan kualitas lingkungan yang sehat. Menurut Undang-undang Republik Indonesia Nomor 36 Tahun 2009 tentang Kesehatan, pasal 162 menyebutkan bahwa upaya kesehatan lingkungan ditujukan untuk mewujudkan kualitas lingkungan yang sehat, baik fisik, kimia, biologi, maupun sosial serta memungkinkan setiap orang mencapai derajat

1) E-mail: imamsuerdi92@gmail.com

2) E-mail : mutshabira@yahoo.co.id kesehatan setinggi-tingginya. Dalam rangka mewujudkan derajat kesehatan, maka perlu adanya tindakan sanitasi yang salah satunya yaitu pengelolaan sampah.Sampah adalah suatu bahan yang terb-uang atau dibuang dari sumber hasil aktivitas manusia maupun alam yang belum memiliki nilai ekonomis.(Depkes RI 1992, h. 30).

Rumah sakit adalah suatu sarana kesehatan yang menyelenggarakan upaya kesehatan masyarakat, 
termasuk didalamnya upaya pencegahan penyakit mulai dari diagnosis dini dan pengobatan yang tepat sampai perawatan intensif dan rehabilitasi orang sakit sampai ketingkat penyembuhan optimal.(Menurut Wikku Adisasmito (2008, h. 33).Berbagai sam-pah yang dihasilkan di rumah sakit dan unit-unit pelayanan kesehatan dapat membahayakan dan menimbulkan gangguan kesehatan bagi peng-unjung dan terutama petugas yang menangani. (Departemen Kesehatan dan WHO, 1991, h. 2)

Sampah rumah sakit merupakan salah satu jenis limbah yang dihasilkan dari kegiatan yang berlangsung di rumah sakit, sampah dipisahkan menjadi dua macam, yaitu sampah medis dan non medis.Sampah medis adalah sampah yang terdiri atas sampah infeksius, patologi, benda tajam, farmasi, sitotoksis, kimiawi, radioaktif, container bertekanan, dan dengan kandungan logam berat yang tinggi. Sampah non medis adalah sampah yang dihasilkan dari kegiatan di rumah sakit diluar medis yang berasal dari dapur, perk-antoran, taman, dan halaman yang dapat dimanfaatkan kembali apabila ada teknologinya. Sampah yang dihasilkan oleh rumah sakit sebagian besar dapat membahayakan siapa saja yang kontak dengannya, karena itu perlu prosedur tertentu dalam pengelolaannya. (Boy Subirosa Sabarguna dan Agus Kharmayana Rubaya, 2011, h. 18).

Rumah Sakit Islam (RSI) Purwokerto adalah salah satu rumah sakit swasta di Kabupaten Banyumas yang bertipe C dengan BOR 75\%. Hasil survey pendahuluan yang berkaitan dengan pengelolaan sampah meng-gunakan metode wawancara kepada petugas bagian penyehatan lingkungan Rumah Sakit Islam (RSI) Purwokerto, didapatkan hasil sampah medis yang diproduksi 25$30 \mathrm{~kg} /$ hari dan sampah non medis 500-650 liter/ hari, dan ditemukan masalah tidak ada jalur khusus pembuangan sampah, jalan menuju ke TPS medis sempit, pengangkutan sampah medis tidak dilakukan dalam waktu 1X24 jam dan lingkungan di sekitar TPS medis banyak terdapat semak-semak.

Tujuan penelitian ini adalah untuk mengetahui Bagaimana pengelolaan sampah di RSI Purwokerto Kabupaten Banyumas Tahun 2015?

\section{METODE DAN BAHAN}

Penelitian ini merupakan penelitian deskriptif, yaitu dengan maksud untuk memperoleh gambaran yang jelas dan nyata tentang sistem pengelolaan sampah di Rumah Sakit IslamPurwokertoKabupaten Banyumas.

Subjek penelitian ini adalah pengelolaan sampah di RS IslamPurwokerto yang meliputi SDA, sarana dan prasarana.

\section{III.HASIL DAN PEMBAHASAN}

Penimbulan Sampah di RS IslamPurwokerto (RSIP) merupakan salah satu tempat yang menghasilkan sampah dalam kegiatannya. Ruangan yang menghasilkan sampah di rumah sakit ini adalah ruangan IGD, IRJ, Bangsal Al-Afiah, Bangsal AlBarokah, Bangsal As-Sakinah, Bangsal As-Salam, Hemodialisa, Radiologi, Laboratorium, Fisioteraphi, IBS, Farmasi, Kasir, Sekertariat, Informasi, Keuangan, Pelayanan, Rumah Tangga, Instalasi Gizi, IPSRS, Kendaraan, IPL, Pendaftaran, Komite Medis, Halaman (Selasar IRJ, Selasar IGD, Selasar Pendaftaran, Selasar Diklat, Selasar Farmasi, Selasar Bangsal dan Kantin). Tempat yang menghasilkan sampah medis dan non medis di RSIP telah diberi tempat sampah khusus yaitu tempat sampah medis dan non medis.

Rata-rata timbulan sampah medis dan non medis dapat dipengaruhi oleh aktifitas yang terjadi di rumah sakit. Berdasarkan perhitungan berat sampah medis dan volume sampah non medis di RSIP dapat diperkirakan rata-rata, yaitu berat sampah medis $27,50 \mathrm{~kg} /$ hari dan volume sampah medis yang dihasilkan adalah 150,85 liter/ hari, sedangkan volume sampah non medis 711,42 liter/ hari. Pada proses penimbulan sampah tidak ada permasalahan karena timbulan sampah medis dan non medis sudah di pisah.

Pewadahan Sampah di RSIP berjumlah 160 buah yang dibagi menjadi 3, yaitu :

1. Tempat sampah medis non infeksius

Konstruksi tempat sampah dalam keadaan baik, karena terbuat dari bahan plastik, kuat, cukup ringan, tahan karat, kedap air, tertutup, tidak bocor dan mudah dibersihkan.Tempat sampah berbentuk persegi panjang dengan volume 25 liter, karena mudah ditempatkan pada setiap ruangan yang menghasilkan sampah medis.

Tempat sampah ini sudah baik, karena dilapisi kantong plastik berwarna kuning dan diganti setiap jam 08.00 WIB dan jam 16.00 WIB/ setelah sampah dibuang jika tempat sampah sudah penuh. Tempat sampah medis berjumlah 36 buah.

Volume dan jumlah tempat sampah memenuhi syarat, karena masih mampu menampung sampah yang ditimbulkan.Tempat sampah diletakkan pada bagian yang sesuai, sehingga ruangan tidak menjadi sempit dan nyaman untuk beraktivitas.

2. Safety box untuk sampah infeksius

Safety box di RSIP manggunakan jerigen, jika tidak ada jerigen dapat memanfaatkan kardus bekas untuk safety box, karana dapat menghemat biaya untuk pembelian safety box. Jumlah Safety box di RSIP berjumlah 9 buah dan memenuhi syarat karena tertutup rapat dan masih cukup untuk menampung sampah infeksius. Safety box ditempatkan pada ruangan yang menghasilkan sampah medis infeksius.

3. Tempat sampah non medis

Konstruksi tempat sampah non medis sudah baik karena terbuat dari bahan yang kuat, cukup ringan, tahan karat, kedap air, tertutup, tidak bocor dan mudah dibersihkan. Tempat sampah non medis dilapisi kantong plastik berwarna 
hitam, kantong plastik diganti pada jam 08.00 WIB dan $16.00 \mathrm{WIB} /$ setelah tempat sampah terisi penuh dan dibuang.

Tempat sampah non medis terletak di dalam ruangan dan di luar ruangan yang menghasilkan sampah.Tempat sampah non medis yang terletak di dalam ruangan berjumlah 89 buah, sedangkan tempat sampah yang berada di halaman berjumlah 26 buah dan berbentuk tabung.

Volume dan jumlah tempat sampah yang berada di dalam dan di luar ruangan memenuhi syarat, karena kapasitasnya mampu menam-pung sampah yang ditimbulkan. Tempat sampah diletakan pada bagian yang sesuai, sehingga terlihat nyaman dan tidak mengganggu aktivitas.

Pengumpulan Sampah di RSIP menggunakan alat yaitu troli khusus yang berukuran 180 liter untuk mengangkut sampah.Troli pengangkut sampah di RSIP sudah memenuhi syarat karena terbuat dari plastik, tertutup, kuat, kedap air, mudah dibersihkan, mudah digunakan dan mampu untuk membawa sampah menuju ke TPS. Jalur pengumpulan sampah belum baik karena tidak melalui jalur khusus. Jumlah troli pengangkut sudah cukup, karena pada setiap ruangan dan halaman sudah mempunyai troli sendiri.

Konstruksi TPS medis dan non medis sudah baik karena terbuat dari tembok, kedap air, tertutup dan mudah dibersihkan. Kapasitas TPS medis kurang memadai karena tidak cukup untuk menampung sampah medis yang diangkut setiap hari Rabu. Sampah di TPS medis berantakaan, karena tidak dibersihkan 1 X24 jam. Letak TPS medis tidak strategis karena jalan menuju ke TPS sempit dan menurun.

Kapasitas TPS non medis sudah baik karena mampu menampung sampah yang dihasilkan rumah sakit. TPS non medis terletak strategis karena jalan menuju TPS lebar dan datar.Sampah di TPS non medis tidak berserakan, karena dibersihkan 1 X24 jam.

Pengangkutan Sampah Medis di RSIP, sampah harus diangkut 1 X 24 jam dan selambatlambatnya 2 X 24 jam. Pengangkutan sampah medis di RSIP kurang baik, karena diangkut setiap hari Rabu pukul 09.00 WIB.Pengangkutan sampah medis yang dilakukan oleh PT. Jasa Medivest sudah baik, karena menggunakan truk khusus sampah medis yang berjenis truk box.Pengangkutan sampah medis kurang efisien, karena kondisi jalan yang miring dan tidak dapat dilewati truk, sehingga petugas harus membawa sampah medis dengan menggunakan troli menuju ke truk pengangkut.Petugas pengangkut sampah sudah menggunakan APD yang memenuhi syarat, yaitu masker, sarung tangan, baju seragam khusus dan sepatu boot.

Pengangkutan sampah non medis sudah baik, karena dilakukan setiap hari. Banyumas pada pukul 11.00 WIB. Pengangkutan sampah non medis mudah, karena jalan menuju TPS lebar dan datar, sehingga truk dapat langsung parkir di depan TPS. Pengangkutan sampah yang dilakukan oleh DCKKTR Kab. Banyumas sudah baik karena menggunakan truk khusus berjenis dum truk.APD yang digunakan petugas pengangkut sampah kurang baik, karena tidak menggunakan APD lengkap, melainkan hanya menggunakan sarung tangan, kaos biasa, celana biasa dan sepatu boot.

Pengolahan sampah di RSIP sudah baik, karena pengolahan sampah medis dilakukan oleh PT. Jasa Medivest yang sudah bersetandar.Pengolahan sampah non medis di RSIP sudah baik, karena RSIP meman-faatkan jerigen dan kardus bekas untuk digunakan sebagai pengganti safety box. Sampah non medis yang sudah tidak dapat dimanfaatkan akan diolah oleh DCKKTR Kab. Kab.Banyumas.

Pemusnahan sampah di RSIP sudah baik, karena sudah melakukan kerjasama dengan PT. Jasa Medivest yang sudah berstandar.Pemusnahan sampah non medis sudah baik, karena sudah melakukan kerjasama dengan DCKKTR Kab.Banyumas, karena mampu menangani sampah dalam kapasitas besar.

Peraturan pengelolaan sampah di RSIP agar terwujud-nya pengelolaan sampah dengan baik, sehingga RSIP melakukan pengelolaan sampah sebaik mungkin berdasarkan aturan dari pemerintah. Peraturan yang digunakan dalam pengelolaan sampah di RSIP adalah PP No. 85 Tahun 1999 tentang Pengelolaan Limbah B3 dan Kepmenkes RI No. 1204/2004 tentang Persyaratan Kesehatan Rumah Sakit.

Penilaian Pengelolaan Sampah di RSIP menurut perhitungan Suharsimi Arikunto 2010 hasil penilaian pengelolaan sampah di RSIP dengan menggunakan ceklist masuk pada kriteria baik, yaitu dengan skor 77,77\%.

\section{IV.KESIMPULAN}

1. Sampah di RSIP ditimbulkan dari ruang IGD, IRJ, Bangsal Al-Afiah, Bangsal Al-Barokah, Bangsal As-Sakinah, Bangsal As-Salam, Hemodialisa, Radiologi, Laboratorium, Fisioteraphi, IBS, Farmasi, Kasir, Sekertariat, Informasi, Keuangan, Pelayanan, Rumah Tangga, Instalasi Gizi, IPSRS, Kendaraan, IPL, Pendaftaran, Komite Medis, Halaman (Selasar IRJ, Selasar IGD, Selasar Pendaftaran, Selasar Diklat, Selasar Farmasi, Selasar Bangsal dan Kantin). Rata-rata berat sampah medis yang dihasilkan adalah $27,5 \mathrm{~kg} /$ hari dan volume sampah medis yang dihasilkan adalah 150,85 liter/ hari, sedangkan volume sampah non medis adalah 711,42 liter/ hari. Jenis sampah medis yang dihasilkan di RSIP, yaitu sampah benda tajam, sampah infeksius, sampah organ tubuh, sampah sitotoksis dan sampah 
farmasi. Jenis sampah non medis yang dihasilkan di RSIP yaitu sampah plastik, sampah kertas, sampah sisa makanan dan sampah daun.

2. Tempat sampah sudah memenuhi syarat yaitu tempat sampah terbuat dari bahan plastik yang kuat, cukup ringan, tahan karat, kedap air, tertutup, tidak bocor dan mudah dibersihkan. Kantong plastik yang digunakan untuk melapisi tempat sampah berwarna sesuai dengan jenisnya. Khusus untuk benda tajam menggunakan jerigen sebagai pengganti wadah safety box.

3. Pengumpulan sampah dilakukan oleh petugas kebersihan setiap hari pada pukul 07.30 WIB. Sampah dikumpulkan oleh petugas kebersihan yang berjumlah 21 orang. Pengumpulan tidak menggunakan jalur khusus dan TPS medis kurang memadai.

4. Sampah medis diangkut setiap hari rabu oleh PT. Jasa Medivest pada pukul 09.00 WIB dan sampah non medis diangkut setiap hari oleh DCKKTR Kab. Banyumas pada pukul 11.00 WIB.

5. RSIP melakukan pengolahan sampah dengan cara memanfaatkan jerigen dan kardus bekas untuk dikunakan sebagai safety box.

6. Pemusnahan sampah medis dilakukan oleh PT. Jasa Medivest dengan membayar Rp. 10.500,- per $\mathrm{kg}$. sampah non medis dilakukan oleh DCKKTR Kab. Banyumas dengan membayar Rp. 350.000.per bulan.

7. Peraturan yang digunakan adalah PP No. 85 Tahun 1999 tentang Pengelolaan Limbah B3 dan Kepmenkes RI No. 1204/2004 tentang Persyaratan Kesehatan Rumah Sakit.

8. Hasil penilaian pengelolaan sampah di RSIP masuk dalam kriteria baik dengan sekor $77,77 \%$.

\section{DAFTAR PUSTAKA}

Boy. S. Sabarguna \& Agus Kharmayana Rubaya, 2011, Sanitasi Air dan Limbah Pendukung Keselamatan Pasien Rumah Sakit, Jakarta.

Departemen Kesehatan \& WHO, 1991, tentang Pengelolaan Limbah Klinis, Jakarta.
Departemen Kesehatan R.I, 1992, Pedoman Sanitasi Rumah Sakit di Indonesia, Jakarta : Pusat Pendidikan Tenaga Kesehatan Departemen Kesehatan R.I.

Departemen Kesehatan Republik Indonesia, 1992, Peraturan Menteri Kesehatan No. 986/MENKES/PER/XI/1992, tentang Persyaratan Kesehatan Rumah Sakit, Jakarta

Kementerian Kesehatan Republik Indonesia. UU RI No. 36 Tahun 2009 tentang Kesehatan. Jakarta : Kemenkes RI.

Kementerian Kesehatan Republik Indonesia. 2004. Keputusan Menteri Kesehatan Republik Indonesia No 1204/Menkes/SK/X/2004, tentang Persyaratan Kesehatan Rumah Sakit. Jakarta.

Lilis Suryani. 2010. Studi Pengelolaan Sampah di Rumah Sakit Umum Hidayah Kabupaten Banyumas Tahun 2010. KTI. Purwokerto : Kementerian Kesehatan RI. Politeknik Kesehatan Semarang Jurusan Kesehatan Lingkungan.

Pruss A., Giroult G., Ruslibrook P. 2005. Pengelolaan Aman Limbah Layanan Kesehatan. Jakarta : EGC.

Suharsimi Arikunto, 2010, Prosedur Penelitian Suatu Pendekatan Praktek, Jakarta: Rineka Cipta.

Tri Cahyono. 2014. Pedoman Penulisan Proposal Penelitian dan Karya Tulis Ilmiah (Edisi Revisi Ketiga), Poltekkes Kemenkes Semarang Jurusan Kesehatan Lingkungan Purwokerto.

Wiku Adi Sasmito. 2008. Audit Lingkungan Rumah Sakit. Jakarta : Rajawali Pers. 